\title{
Methodology for Rapid Technology Valuation with Restricted Incomes
}

\author{
Vega-González Luis Roberto (Corresponding author) \\ Centro de Ciencias Aplicadas y Desarrollo Tecnológico \\ Universidad Nacional Autónoma de México, Circuito Exterior S/N, Ciudad Universitaria \\ A.P. 70-186, Delegación Coyoacán, CP 04510, México D.F., México \\ Tel: 55-5622-8602 ext. 1135 E-mail:1rvg@unam.mx; roberto.vega@ ccadet.unam.mx
}

\author{
Rivera-Velasco Gustavo \\ Instituto Tecnológico Superior de Irapuato \\ Coordinación de Ingeniería en Gestión Empresarial
}

Tel: 462-606-7628Ｅ-mail: gustavo.rivera@itesi.edu.mx

Received: December 14, 2015 Accepted: December 27, 2015

doi:10.5296/ber.v6i1.8717

URL: http://dx.doi.org/10.5296/ber.v6i1.8717

\begin{abstract}
The aim of this study is to present a rapid methodology to valuate the technology developed at $\mathrm{R} \& \mathrm{D}$ university institutions. The methodology is a variation of the classical Income method and is based on the calculation of total permutations obtained from the data of an array of highly punished yearly incomes expected for previously defined multi-scenarios and the statistical averaging of such permutations. The method is applied to valuate an energy saving technology device, in order to illustrate its process of implementation. This methodology results in a practical and useful method for obtaining a first monetary value for the technology which allows the realization of vital and rapid decision making in a global economic dynamic in which the speed and reliability in decision making is vital for the competitiveness. Final results of the presented case shown that the presented methodology can be adapted to be used to obtain a first monetary value for almost any field new technology products with promising commercial expectations, which could have many different application opportunities. It can be used for the R\&D developers in order to obtain
\end{abstract}




\section{Macrothink}

the value of the technologies under development along the different prototype versions available. Generally speaking, valuation techniques are time consuming and it is difficult to have some results that permits to get into first negotiations. The methodology presented can help to solve this problem allowing extra time to obtain additional data like final product production costs to improve the accuracy of the estimations.

Keywords: Technology valuation, Restricted income method, Energy saving technology

\section{Introduction}

The importance of the products of research projects, technological development and innovation, as pillars of economic development of a nation, was recognized a long time ago in the initial studies of Schumpeter (1934/2008). Since then, hundreds of publications have been written trying to explain the factors favoring these phenomena.

When the research projects, development and innovation (R\&D+i) accomplished in public universities end, it is required the transfer of the resulting technology to the public and private organizations in society, in order that the technology reaches the market producing important impacts on society. Technology transfer is one of the fundamental activities of technology management. It requires important activities such as identifying opportunities, preparing and presenting technical and economic proposals and of course of the technological valuation.

Whatever the form of technology transfer, the determination of the price or valuation represents an activity of paramount importance to get into a negotiation process; nevertheless, this process entails a particular set of difficulties in the developing countries, as can be seen in Figure 1. The first two are the complexity and uncertainty when there is no a benchmark available (Vega, 2003).

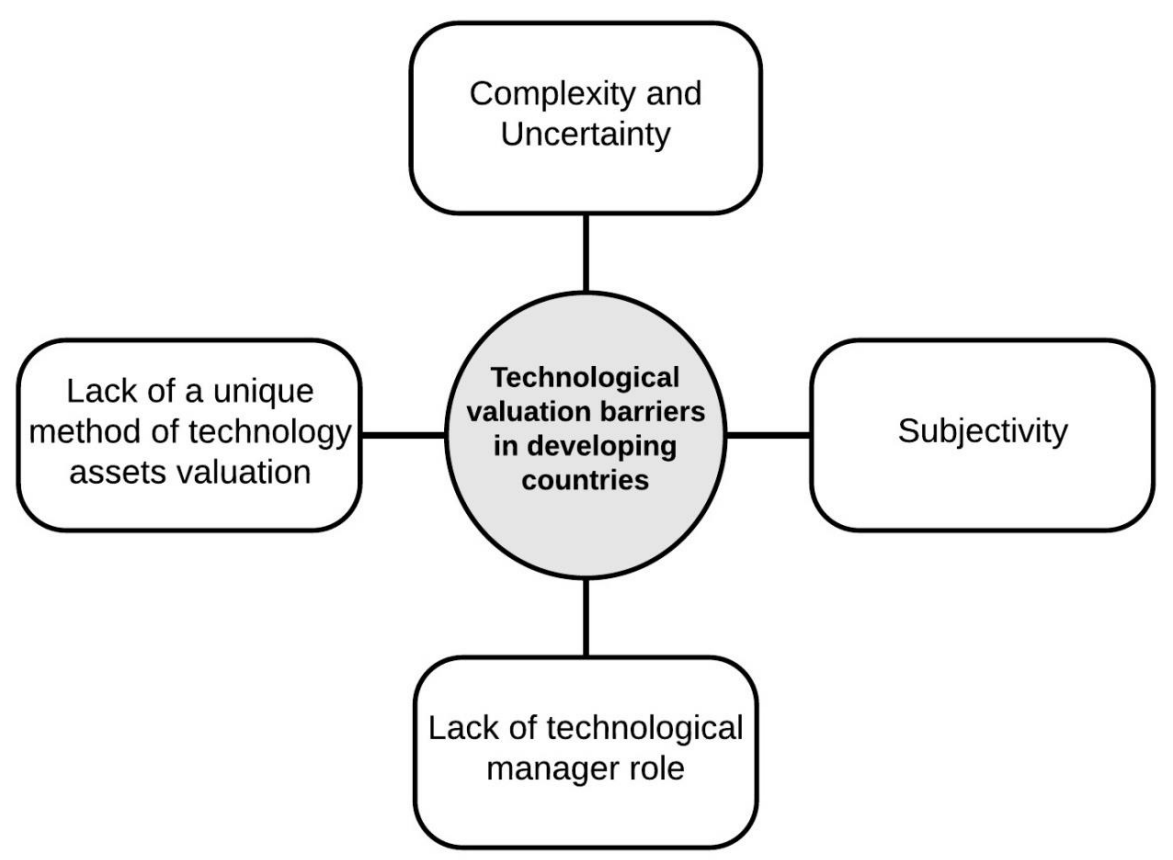

Fig 1. Technological valuation barriers in developing countries. 
For Hunt, et al, (2007), one of the key challenges facing those who are financially valuing projects, is uncertainty and ambiguity; therefore, with the purpose of making practical decisions, we must develop valuation methodologies that can help to reduce uncertainty quantitatively. In cases where a mere reduction of uncertainty could be enough, it is not necessary the elimination of it, (Douglas, 2014). Nonetheless, when it is required the valuation for high technology as aerospace technology, it must be considered the back up of consultants through an expert elicitation process to reduce the uncertainty of the valuation. (Farooq, 2012)

Another complication is the valuation subjectivity that occurs between the technical and organizational spheres. Technical in the sense that there are valuation methodologies that just offer approximated results. The subjectivity related to the organization occurs because there are different value contexts for every organization (Echeverri \& Franco, 2012).

Additionally, there is a general lack of technological managers at universities of the developing countries. This presents a number of problems; for example, the laboratory managers, engineers and technical people, commonly occupied by their academic activities can ignore, exaggerate or not register necessary information when they value technology; even more, they also can make a priori judgments and underestimate the real value of the technology, with the aim of attracting customers or sponsors this situations could be prejudicial to any further negotiation. (Vega, 2011). Besides of that, there is not a unique method, universally valid for the valuation of technology assets; that is, there are multiple options to consider such as research and development costs, expected profits, market value or prevailing standard in the industry, among many others.

Today as never before, new technology is produced by $R \& D$ university institutions to respond to the needs and market requirements; therefore, to facilitate the technology transfer and the transaction negotiations, valuation should be accelerated in order to meet the needs of both the university institutions and the licensees. Besides, punish financial variables used in the valuation process adds realism and reliability to the final valuation.

In response to the assumptions described above, this article shows the development and application of a methodology of rapid technological valuation, characterized by restrictions on data expected sales in various scenarios.

This technique was developed taking as a case study a technology device for lighting energy efficiency created in the Faculty of Engineering of the National Autonomous University of Mexico (UNAM).

\section{Literature Review}

Dong-Hyun et al. (2007), have noted that technology innovation plays a vital role in building national competitiveness. They note that in Korea every state and corporation is concentrating on fortifying their global competitiveness with high technology development capability that is difficult to imitate. In order to facilitate the advancement and development process of high technology, the market for technology transfer must be promoted and accordingly, much attention is needed in valuating technology. 
Several authors have addressed the technology valuation as an input for the technology transfer (TT) process from universities and research and development institutions to industrial firms; nevertheless, the process can be used for the interchange of technology knowledge assets among private firms through negotiation. Besides of that, sometimes the valuation of technology intangible assets is required for family law purposes. (Reilly, 2015). Also, Chiesa \& Gilardoni (2015) point out that in recent years companies are often involved in decisions concerning not only to the external acquisition of technology, but also to the opportunity to sell or to cooperate with other firms. However the existing methods for technology valuation are subject to drawbacks and limitations. (Park \& Park, 2002).

For Holmes (2009), as certainty of value for IP never reaches 100\%, technology-transfer professionals often be overwhelm by the complexity of the data and the requirements of valuation techniques and become skeptical of its applicability and utility for technology transfer. Nevertheless, Vega \& Saniger, (2010) have stated that nearly always the persons who perform technology valuations have trouble identifying what is the best approach to valuing intangibles, but they can draw on the most common approaches available in the current technology valuation literature: (a) monetary value models; classified into three basic approaches, namely cost approach, market approach, and income approach; (b) intangible assets valuation, (c) risk approach; (d) real options financial models; (e) contingency valuation models and (f) pragmatic models.

Wang \& Edmondson (2014) noted that both public and private technologies need to be transferred in order to be used in large scale. They also consider that the main technology pricing approaches are cost, market and income. Tools facilitating these approaches include discounted cash flow (DCF), options theory, and probabilistic decision trees. DCF is often the preferred method both for practitioners and theorists, while options theory is popular for early-stage ideas. (Boer, 2000).

The cost approach is based on the economic principle of substitution that postulates that a prudent buyer would pay no more and a willing seller could command no more for a technology than the cost to create an intellectual asset of equal desirability and utility. Specifically, there are two fundamental types of cost quantified in cost approach, namely reproduction cost and replacement cost. The applicability of cost approach is quite limited. The market approach is rather simple and direct method. It argues that the value of technology be equivalent to what others in the market place have judged it to be. Therefore, the prerequisite for market approach is the existence of active public market and transaction data of comparable properties.

The income approach is based on the rationale that value is determined by income-producing capability of the subject technology. Specifically, the value is measured by Net Present Value (NPV) of the economic benefit (cash receipts less cash outlays) over the life of the technology. The income approach is considered to be best suited for the valuation of intellectual property such as patents, trademarks and copyrights.

Lately, several authors have applied technology valuation methodologies for specific technology fields, among others, we have valuations for construction technology (Se Joon, et 
al., 2010), for organic process (Cannon \& Breen, 2010), for Photovoltaic technology (Chanwoong \& Juneseu, 2014); for manufacturing systems (Schuh, 2012); for Magnetic Resonance Imaging (Blankart et al., 2008); for life sciences technology (Mayhew, 2010; Bogdan \& Villiger, 2010); and valuing oil production by using real options (Boer, 2000).

In recent years, new valuation methodologies have been proposed, and among them, real option-based approaches have emerged. Trigeorgis (1996), cited by Yan et al., (2010), claimed that neither traditional capital budgeting methods nor discounted cash flow approaches could cope with the operation flexibility options and other strategic aspects of various projects but the application of option techniques has resulted in the correct solution. Today, real options techniques are combined with Fuzzy Set Theory.

Real Options applied to R\&D results are similar to the evaluation of financial investment opportunities. A financial opportunity involves a sequence of cash flows: (1) an exploratory investment searching new technology opportunities; (2) the investment in production facilities; (3) cash flow streams coming from technology sales until production is no longer economical or its life cycle has expired. To build an options tree, it is required to take in account at least two types of risks, the one associated with the technology feasibility and the market risk, which is an estimation of the probability to be successful selling the technology at the focal market, situation that surely must impact the total incomes amount of the option. Immediately a second option tree must be built for an alternative technology and so on; the idea is to compare with many options as possible. The best technology to invest in, should be the one that get the most cash flow, with the higher benefit/cost relationship, using same or similar restrictions in the calculations realized. (Boer, Op. Cit., page 3).

\section{Materials and Methods}

In order to measure the monetary value of this pre-competitive state technology, we used a modified income method using estimates and projections of expected sales of technology in 3 business sceneries: (i) low sales scenario, (ii) medium sales scenario \& (iii) high sales scenario. One of the special features of this methodology is that in all the sceneries we assumed high restrictions on its financial performance. The projection of multiple scenarios allowed us to create a matrix with different values for the various existing commercial applications of technology. By last, we get our estimated final value by averaging all the amounts obtained applying the combination and permutation of the values in the array above (Fig. 2). 


\section{Macrothink}

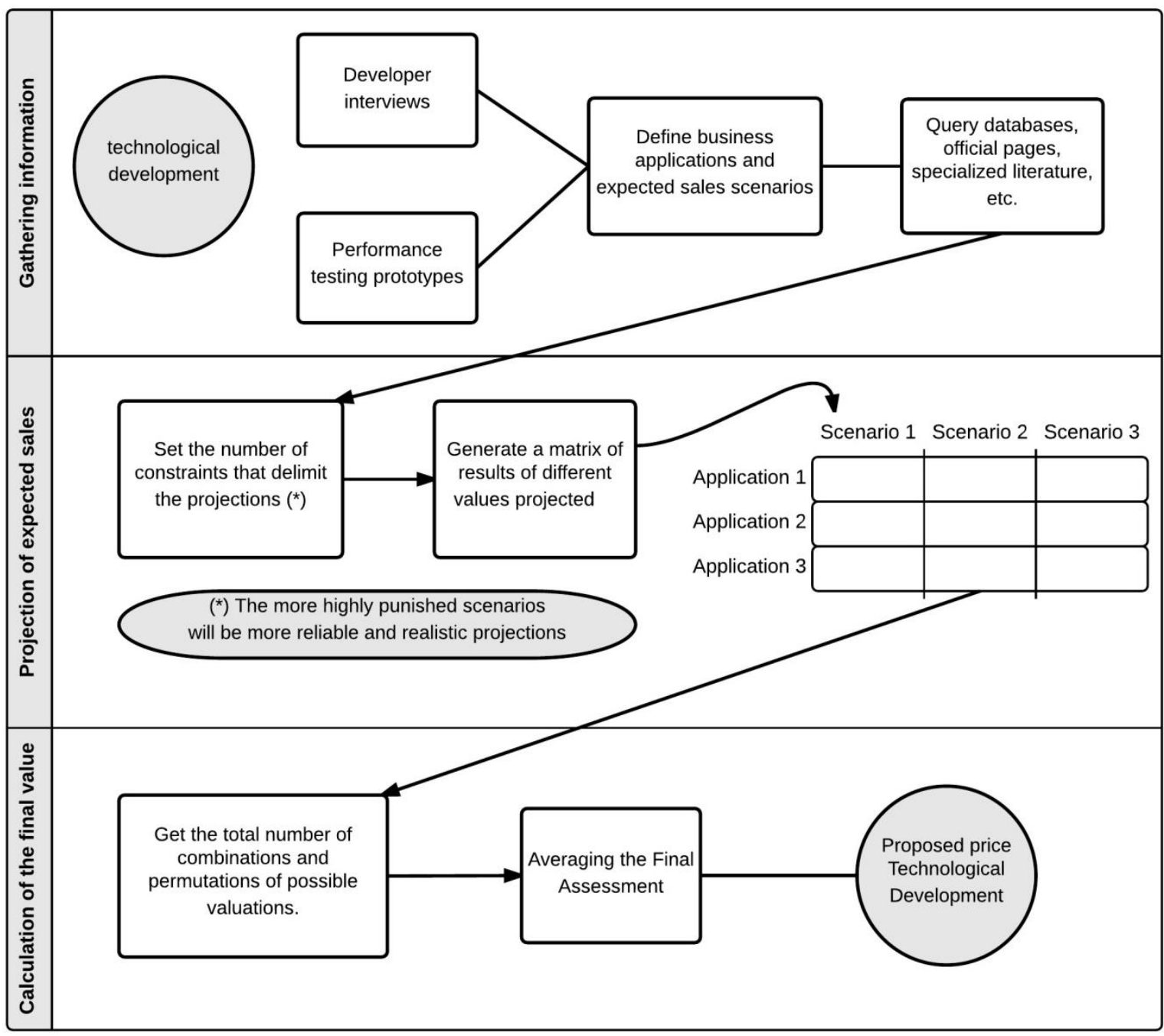

Figure 1. Flowchart for the rapid technological valuation technique presented.

Source: Based on Vega-G. L. R., (2003). Evaluación, avalúo y ciclo de vida de la tecnología parte II. Revista de Ingeniería Investigación y Tecnología, UNAM. Vol. IV, No. 4, México.

The main features of this approach are its simplicity and speed of implementation along with the reliability and realism of the final result. We could not use real options in the proposed methodology because the technology evaluated is in the first development stages having some patents but no factory production data available.

\section{Application of the Valuation Methodology for Lighting Technology Energy Saving}

The following are the various steps shown in the flowchart of Figure No. 2

\subsection{Gathering Information}

Previous to performing any type of measurement it is important to understand clearly the context in which our valuation will be developed, so we need answers for the following questions: Which commercial applications of the technology will be included in the valuation?, Which problem does it solve?, Which market segment would be interested in acquiring the technology?, Which government agencies regulate the performance of this 
technology in the market?, Are there competing technologies?, Could a product with these specifications have a major impact on the market?, Is there a big enough market for such technology ?, and so on. We can find answers to these and other relevant questions, by applying interviews to the technology developers, watch performance testing and studying the development log, in addition to recovering official information from databases, websites and literature.

In the case of the energy saving technology valued, a few interviews were arranged with the developers of the technology, who also conducted tests of prototypes in comparison with other existing technologies on the market. The applications identified for the technology were: (i) lighting for home use, (ii) lighting for offices and (iii) luminaries for use on public roads.

\subsection{Projection of Expected Sales}

This is the most elaborate stage of the process, as it involves estimating and projecting expected sales of the technology applications valued in different sceneries. However, in this part of the process is vital to remember that the incomes data are only estimates as it is unknown which be the behavior and actual acceptance of the technology in the market. Special care is needed to ensure that the restrictions that will be imposed to our projections are quite realistic and independent of the performance of the technology on the market, to avoid falling into misleading results of the valuation.

Once obtained the various sales projections and the estimated valuations we proceeded to calculate the technology value in each stage of the business scenery through the implementation of the international rule which gives to the technology developer $5 \%$ of total sales of technological products (KPMG, 2012). With this data we built a matrix taking as rows, the commercial applications of the technology and as columns the business scenarios projected. The matrix concentrates all the values obtained.

Table 1 shows specific market data for the calculation of expected sales in the lowest scenario. 5 randomly selected Mexican cities with populations between 500,000 and 1 million inhabitants according to the census published by the Instituto Nacional de Geografía, Estadística e Informática, (INEGI, 2010).

Table 1. Population used to calculate the low scenario.

\begin{tabular}{ccc}
\hline City & $\mathbf{N}^{\circ}$ of population & $\mathbf{N}^{\circ}$ of households \\
\hline Acapulco & 789,971 & 205,485 \\
\hline Aguascalientes & 797,010 & 202,059 \\
\hline Chihuahua & 819,543 & 237,106 \\
\hline Morelia & 729,279 & 190,434 \\
\hline San Luis Potosi & 772,604 & 199,277 \\
\hline
\end{tabular}

Table 2 shows specific market data for the calculation of expected sales in the medium scenario. We choose the 5 cities with the largest number of Internet search of the term "LED 


\section{1) Macrothink}

lamp" in September 2014 according to the marketing tool "Google Trends"

Table 2. Population used to calculate the medium scenario.

\begin{tabular}{cccc}
\hline City & Density search & $\mathbf{N}^{\circ}$ of population & $\mathbf{N}^{\circ}$ of households \\
\hline Merida & 100 & 830,732 & 229,635 \\
\hline Queretaro & 95 & 801,940 & 205,832 \\
\hline Saltillo & 83 & 725,123 & 187,764 \\
\hline Puebla & 77 & $1,539,819$ & 406,408 \\
\hline CDMX & 77 & $8,851,080$ & $2,453,031$ \\
\hline
\end{tabular}

Table 3 shows specific market data for the calculation of expected sales in the high sales scenario. It was constructed from the 5 most densely populated metropolitan areas in Mexico according to the study conducted by INEGI entitled "Delimitation of the metropolitan areas of Mexico 2010"

Table 3. Population used to calculate the high scenario.

\begin{tabular}{ccc}
\hline Metropolitan area & $\mathbf{N}^{\circ}$ of population & $\mathbf{N}^{\circ}$ of households \\
\hline Mexico Valley & $20,116,842$ & $5,029,210$ \\
\hline Guadalajara & $4,434,878$ & $1,099,132$ \\
\hline Monterrey & $4,106,054$ & $1,060,332$ \\
\hline Puebla-Tlaxcala & $2,728,790$ & 682,197 \\
\hline Toluca & $1,936,126$ & 454,539 \\
\hline
\end{tabular}

To define and control the performance of the sales projections on the scenarios, the following constraints were used:

- Sales were calculated for five years, which is a medium commercial period during the life cycle of technology.

- We assume only the initial purchase of one product per customer, and an increase of $25 \%$ in sales per year.

- We take an introductory price of: $\$ 100.00$ Mexican pesos (MXN) for the home device, $\$ 1,000 \mathrm{MXN}$ for the industrial luminary and $\$ 2,000 \mathrm{MXN}$ for the public luminary; these prices will be projected with an annual increase of $3 \%$ taken as the probable inflation rate for Mexico during 2014.

- Only four socioeconomic categories (A / B, C and C+), will be used for projecting consumption of the home device, as was proposed in 2014 by the Mexican Association of Market Research Agencies and Public Opinion (AMAI, for its acronym in Spanish), depending on the standards of living and the average income in the country. According to AMAI in practice, people intends to have all the necessary items to make life easier at home; therefore, their greatest aspiration is to have technological equipment. Table 4 
shows the distribution of socioeconomic levels shown $\mathrm{A} / \mathrm{B}, \mathrm{C}+$ and $\mathrm{C}$, and the percentage covered by them on the market. We supposed that only $38 \%$ of households in the aforementioned cities will consume our product. This percentage is very conservative, but is one of the restriction levels for making sales projections more real.

Table 4. Percentage of socioeconomic levels used in the valuation

\begin{tabular}{cc}
\hline Level & Average percentage of households \\
& \\
\hline $\mathrm{A} / \mathrm{B}$ & $6.8 \%$ \\
\hline $\mathrm{C}+$ & $14.2 \%$ \\
\hline $\mathrm{C}$ & $17 \%$ \\
\hline Total & $38 \%$ \\
\hline
\end{tabular}

- Initially we assume only $10 \%$ of penetration of the segmented market, with an increase of $10 \%$ annually.

- The potential market for office luminaries was assumed as the sum of the following business units (DENUE, 2014).

$\circ$ Wholesale trade

o Educational services

$\circ$ Health and welfare

- To segment the market for public luminaries we used the luminary census conducted for the Mexico City by the Agency for Urban Management CDMX (2014), where it is detailed the number and percentage of light sources in each of the delegations of Mexico City.

- The rate of market growth was assumed as $2.6 \%$ per year, according to INEGI data on population growth (2010).

Finally, we used the pragmatic rule which states that from the profits generated the inventor should receive 25\%. (Goldscheider, 2002). This is roughly equivalent to say that the technologist average inventor must charge $5 \%$ of total sales of technological products (KPMG, 2012). Wilson, (2012) confirms that in practice the average royalty rate for inventions is within the range of 5-6\% of the gross revenue for the products that utilize the inventions.

It is required to note that raising the level of the restrictions; we indirectly provoke highly punished scenarios in the projected sales. After developing sales projections, we calculate the Net Present Value (NPV) on the amounts obtained by the application of the international rule of $5 \%$ to get the upper level valuation scale. The obtained values were concentrated in the matrix shown in Table 5 . 
Table 5. Matrix valuations.

\begin{tabular}{lccc}
\hline & Low scenario & Medium scenario & High scenario \\
& & & \\
\hline Home luminaries & $6,548,693$ & $22,049,302$ & $50,693,545$ \\
\hline Office luminaries & $1,225,860$ & $3,845,569$ & $7,147,728$ \\
\hline Public luminaries & $5,814,000$ & $10,336,000$ & $17,850,000$ \\
\hline
\end{tabular}

Note. All amounts are expressed in Mexican pesos.

\subsection{Calculation of the Final Value}

The first step to obtain the final value is to find the number of possible permutations that are formed by combining the values of the matrix valuations, under the following restrictions:

- It can be chosen the same stage for the 3 different applications of the technology.

- It can't be chosen more than one scenario for the same application of technology.

To do this, it is necessary to calculate first the number of permutations for technological applications and the number of combinations for the proposed scenarios. At once we describe how to obtain the values required.

4.3.1 Calculation of the Number of Permutations for the Different Applications of the Lighting Technology.

Since technological applications only accept the election of one of its scenarios for each possible combination of upper valuation values, then the formula for permutations without

repetition will be used: $\frac{n !}{(n-r) !}$ then is necessary to multiply this value of possible permutations for the number of technological applications of the luminaries. Thus we obtain the following equation:

$$
N^{l m}=\left(\frac{n^{l m !}}{\left(n^{l m}-r\right) !}\right)\left(n^{l m}\right)
$$

where:

$N^{l m}=$ Number of permutations for luminaries applications.

$n^{\operatorname{lm}}=$ Number of technological applications for the luminaries.

$r=$ Number of eligible technological application of luminaries scenarios.

Substituting the values: 


$$
\begin{gathered}
N^{l m}=\left(\frac{3 !}{(3-1) !}\right) \\
N^{l m}=\left(\frac{6}{2}\right)(3) \\
N^{l m}=9
\end{gathered}
$$

\subsubsection{Calculation of the Number of Combinations for the Scenarios}

For this calculation we stated acceptable to select the same scenario for every one of the 3 different applications of the technology, for this reason the formula of repetition permutations will be used, that is: (n!)

After that, we multiply this value by the number of scenarios, so we get the following equation: $N^{e s}=\left(n^{e s}\right)\left(n^{e s}\right)$

In which:

$N^{e s}=$ Number of combinations for the scenarios.

$n^{\text {es }}=$ Number of scenarios.

Substituting the values:

$$
\begin{gathered}
N^{e s}=(3 !)(3) \\
N^{e s}=(6)(3) \\
N^{e s}=18
\end{gathered}
$$

\subsubsection{Calculating the Total Number of Permutations for The Valuations}

Once obtained the number of permutations for applications luminaries $\left(N^{I m}\right)$ and the number of combinations for scenarios $\left(N^{e s}\right)$ both values are added to obtain the total number of permutations for possible values $(\mathrm{N})$, so the following equation is obtained:

$$
N=N^{l m}+N^{e s}
$$

Substituting the values: 


$$
\begin{gathered}
N=9+18 \\
N=27
\end{gathered}
$$

Once we know the total number of permutations the next step is to calculate the final valuation.

\subsubsection{Final Valuation}

The final valuation ( $\mu a t$ ) is obtained averaging the sum of the 27 different obtainable values

(Eat) over the total number of permutations $(N)$. Table 6 lists the 27 different possible valuations for all the permutations. Adding all the values, the total amount obtained was 1 billion 129 million 596 thousand 268 Mexican pesos.

The Final Value ( $\mu$ at), becomes the average of the values list, as follows:

$$
\mu a t=\frac{\Sigma a t}{N}=\$ 41,836,899.00 \text { pesos }
$$

The resultant value for the energy saving technology applied to luminaries with 3 commercial applications: luminaries for home, luminaries for offices and luminaries for public lighting, was $\$ 41,836,899.00$ Mexican pesos, (About $\$ 2,460,994.00$ USD at rate of change of $\$ 1.00$ USD/\$17.00 Mexican pesos). Figure 4 shows the result rounded to 42 million pesos.

Table 6. Valuations obtained by sales projections in the different sceneries

\begin{tabular}{|c|c|c|c|}
\hline $\mathbf{N}^{\circ}$ & $\begin{array}{c}\text { Possible valuations (Mexican } \\
\text { Pesos) }\end{array}$ & $\mathbf{N}^{\circ}$ & $\begin{array}{c}\text { Possible valuations (Mexican } \\
\text { Pesos) }\end{array}$ \\
\hline 1 & $13,588,553$ & 15 & $43,744,871$ \\
\hline 2 & $18,110,553$ & 16 & $35,011,030$ \\
\hline 3 & $25,624,553$ & 17 & $39,533,030$ \\
\hline 4 & $16,208,262$ & 18 & $47,047,030$ \\
\hline 5 & $20,730,262$ & 19 & $57,733,405$ \\
\hline 6 & $28,244,262$ & 20 & $62,255,405$ \\
\hline 7 & $19,510,421$ & 21 & $69,769,405$ \\
\hline 8 & $24,032,421$ & 22 & $60,353,113$ \\
\hline 9 & $31,546,421$ & 23 & $64,875,113$ \\
\hline 10 & $29,089,162$ & 24 & $72,389,113$ \\
\hline 11 & $33,611,162$ & 25 & $63,655,272$ \\
\hline 12 & $41,125,162$ & 26 & $68,177,272$ \\
\hline 13 & $31,708,871$ & 27 & $75,691,272$ \\
\hline 14 & $36,230,871$ & $\mathbf{\Sigma a t}$ & $\mathbf{\$ 1 , 1 2 9 , 5 9 6 , 2 6 8}$ \\
\hline
\end{tabular}




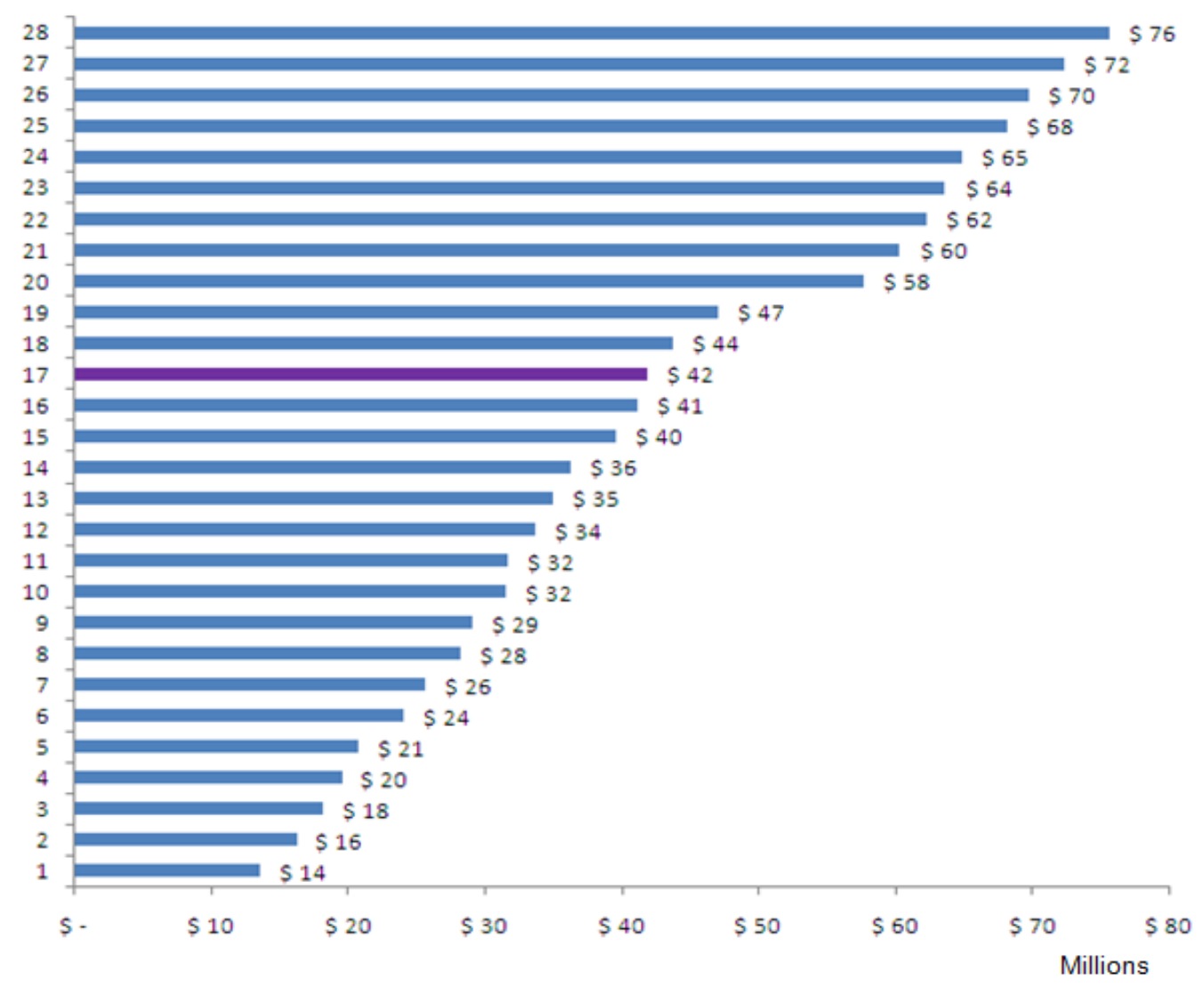

Fig. 4. Comparison of the 27 possible valuations with the final value average.

Note: the amounts are rounded, the final value suggested is highlighted.

\subsubsection{Final Valuation}

The final valuation ( $\mu a t$ ) is obtained averaging the sum of the 27 different obtainable values

(Eat) over the total number of permutations $(N)$. Table 6 lists the 27 different possible valuations for all the permutations. Adding all the values, the total amount obtained was 1 billion 129 million 596 thousand 268 Mexican pesos.

The Final Value ( $\mu a t)$, becomes the average of the values list, as follows:

$$
\mu a t=\frac{\Sigma a t}{N}=\$ 41,836,899.00 \text { pesos }
$$

The resultant value for the energy saving technology applied to luminaries with 3 commercial applications: luminaries for home, luminaries for offices and luminaries for public lighting, was $\$ 41,836,899.00$ Mexican pesos, (About $\$ 2,460,994.00$ USD at rate of change of $\$ 1.00$ USD/\$17.00 Mexican pesos). Figure 4 shows the result rounded to 42 million pesos. 


\section{Conclusions}

Valuation is a highly subjective process; therefore not all the valuation procedures give the same results. Nevertheless, a method of valuation well supported, is a required procedure for the negotiations behind the technology transfer.

As it happens in different commercial transactions, sometimes the technology transfer success depends on the agenda of the interested client. Real well founded negotiation data is frequently urgently required in order to catch the opportunity. In the technology negotiation scenery the main input is the value of it. On the other side, we know that generally speaking, valuation techniques require a long time and it is difficult to have some reliable results permitting to get into first negotiations. The methodology presented can help to solve this problem allowing extra time to obtain additional data like final product production costs to improve the accuracy of the estimations. Besides, covering both the value of tangible and intangible assets, using the income modified method with restricted sales scenarios, reduces the uncertainty in the benefit-risk opportunity index, always implicit in the acquisition of new technology.

Making certain assumptions, it was possible to reduce the uncertainty of the value for the lighting energy saving technology, by assigning a specific monetary value for the technology products that uses it. The valuation was reached within the established standards of speed, simplicity, objectivity and certainty, due to the following features of the methodology:

- It uses market related information technology and communication as: Google Trends and the National Statistics Directory of Economic Units (DENUE).

- Review of official data bases, based on macro research projects with high reliability and widely used as those issued by institutions such as: (a) National Institute of Statistics and Geography (INEGI); (b) Mexican Association of Market Intelligence Agencies and Public Opinion (AMAI); (c) Agency of Urban Management in Mexico City (AGUCDMX); (d) Bank of Mexico.

The final valuation was reached calculating the average of the 27 different values obtained by the proposed multi-stage valuation methodology; it was achieved by using logical and realistic criteria to delimit the sales projections of the valuated technology in order to avoid economic perturbations that could confuse the appraisal results. Methodology presented can be adapted and used by any $R \& D$ public or private institution requiring rapid but accurate technology value results.

\section{References}

Agency of Urban Management in Mexico City. (2014). The Mexico City Government signs agreement to replace $340 \quad 000$ luminaries. Recovered from http://www.agu.df.gob.mx/sintesis/index.php/el-gdf-firma-convenio-para-sustituir-340-mil-lu minarias/

AMAI. (2014). Socio-economic levels. Recovered from http://nse.amai.org/nseamai2/

Bank of Mexico. (2014). Inflation rates. Recovered from 
http://www.banxico.org.mx/portal-inflacion/inflacion.html

Blankart, R, Schreyogg, J., Busse, R., (2008). Performance of reimbursement schemes in valuation of technologies: The example of Magnetic Resonance Imaging. Technology and Health Care. 16, 171-182

Boer, F. P. (2000) Valuation of technology using Real Options. Research Technology Management, 26-30.

Bogdan, B., Villiger, R., (2010). Valuation in Life Sciences, Third Edition, Springer, 370. http://dx.doi.org/10.1007/978-3-642-10820-4

Cannon, K. C., Breen, M. P., (2010). Organic Process Technology Valuation: Cyclohexanone Oxime Syntheses. Journal of Chemical Education. 87(1), 66-68. http://dx.doi.org/10.1021/ed800006a

Chanwoong, J., Juneseuk, S., (2014). Long-term renewable energy technology valuation using systemdynamics and Monte Carlo simulation: Photovoltaic technology case. Energy, 66, 447-457. http://dx.doi.org/10.1016/j.energy.2014.01.050

Chiesa, V., Gilardoni, E., (2015). The valuation of technology in buy-cooperate-sell decisions. European Journal of Innovation Management, 8(2), 157-181. http://dx.doi.org/10.1108/14601060510594710,

DENUE (2014). Various consultations by economic unit and geographic region. Available in http://www3.inegi.org.mx/sistemas/mapa/denue/default.aspx

Dong-Hyun, B., Wonsik, S., Kil-Pyo, H., Hum K., (2007). A technology valuation model to support technology transfer negotiations. $R \& D$ Management, 37(2), 123- 138. http://dx.doi.org/10.1111/j.1467-9310.2007.00462.x

Douglas, W. (2014). How to measure anything: finding the value of "intangibles" in Business. John Wiley \& Sons, Inc., Hoboken, New Jersey.

Echeverri, R., \& Franco, L. (2012). Rating technology for trading purposes. Fondo Editorial ITM, Medellín Col.

Farooq, B. A. M., (2012). A methodology for uncertainty quantification in quantitative technology valuation based on expert elicitation. Georgia Institute of Technology. Dissertation to obtain the Degree of Doctor of Philosophy in the School of Aerospace Engineering.

Goldscheider, R., Jarosz, J., Mulhern, C., (2002). Use of the 25 Per Cent Rule in Valuing IP. Les Nouvelles., 123-135.

Google Trends. Search term: "LED lamp". Asked in September 2014 in https://www.google.com.mx/trends/explore\#q=lampara+led\&geo=MX

Holmes Jr. J. S., (2009). Societal and economic valuation of technology-transferdeals. Acta Astronautica. 65, 834-840. http://dx.doi.org/10.1016/j.actaastro.2009.01.070 
Hunt, F., Thorn, V., Mitchell, R., Probert, D., Phaal, R., (2007). Internal technology valuation: real world issues. PICMET Proceedings. August, Portland, Oregon-USA, 1736-1742. http://dx.doi.org/10.1109/picmet.2007.4349498

INEGI. (2010). Delimitation of the metropolitan areas of Mexico 2010 in http://www.inegi.org.mx/Sistemas/multiarchivos/doc/702825003884/DZM20101.pdf

INEGI. (2010). Mexico in numbers: National information, by state and municipality. Recovered from http://www3.inegi.org.mx/sistemas/mexicocifras/

KPMG. (2012). Profitability and royalty rates across industries: Some preliminary evidence. Publication number: 120985. Publication date: November 2012

Park, Y., Park, G., (2002). A new method for technology valuation in monetary value: $\begin{array}{llll}\text { procedure and } \quad \text { Technovation, } & \text { 387-394. }\end{array}$ http://dx.doi.org/10.1016/S0166-4972(02)00099-8

Mayhew, S., (2010). Practical approaches to early stage life sciences technology valuations. Journal of Commercial Biotechnology. 16(2), 120-134. http://dx.doi.org/10.1057/jcb.2009.31

Reilly, R. F., (2015). Family Law Valuation of Technology Intangible Assets, American Journal of Family Law. Spring, 29(1), 16-26.

Schuh, G., Schubert, J., Wellensiek, M., (2012). Model for the Valuation of a technology Established in a Manufacturing System. Procedia CIRP, 3, 602-607. http://dx.doi.org/10.1016/j.procir.2012.07.103

Schumpeter, J. (1934/2008). The theory of economic development. Journal of Comparative Research in Anthropology and Sociology. 3(2).

Se Joon, H., Jong Won, S., Young Suk, K., Sang Hyeok, K. (2010). Construction Technology Valuation for Patent Transaction KSCE, Journal of Civil Engineering, 14(2), 111-122. DOI 10.1007/s12205-010-0111-y

Trigeorgis. (1996). Real Options: Managerial Flexibility and Strategy in Resource Allocation [M]. The MIT Press, Cambridge Massachusetts.

Vega-G. L. R; Saniger B. J. M., (2010). Valuation Methodology for Technology Developed at Academic R\&D Groups. Journal of Applied Research and Technology, México; Vol. 8, No. 1; pp. 26-43. ISSN 1665-6423

Wang, B., Edmondson, J. C., (2014). About Technology Valuation. Proceedings of PICMET: Infrastructure and Service Integration, 1137-1144.

Wilson, B. S., (2012). Retrospective valuations of intellectual property. J Technol Transfer. 37, 124-133. DOI 10.1007/s10961-010-9172-9

Yan, L., Hong, Z., Huang, H., (2010). Review on methods of new technology valuation. International Conference on E-Business and E-Government, IEEE, 1932-1935. http://dx.doi.org/10.1109/icee.2010.488 


\section{Copyright Disclaimer}

Copyright for this article is retained by the author(s), with first publication rights granted to the journal.

This is an open-access article distributed under the terms and conditions of the Creative Commons Attribution license (http://creativecommons.org/licenses/by/3.0/). 